\title{
Un fragmento con Génesis 4,4-15 en árabe samaritano, y una adición en hebreo samaritano, conservado en la Colección Taylor-Schechter de la Guenizá (T-S Ar.1a.136)*
}

\author{
Friedrich Niessen (ל) \\ Taylor-Schechter Genizah Research Unit, Cambridge \\ Juan Pedro Monferrer-Sala ** \\ Universidad de Córdoba ${ }^{* * *}$
}

En este estudio se analiza un fragmento manuscrito en árabe samaritano conservado en la Colección Taylor-Schechter de Cambridge con el objeto de precisar a qué tipo de versión de la familia árabe samaritana del Pentateuco pertenece.

Palabras Clave: Árabe samaritano; Pentateuco; manuscrito: Guenizá de El Cairo; Colección Taylor-Schechter.

A fragment with Genesis 4:4-15 in Samaritan-Arabic, and an Addition in Samaritan Hebrew, preserved in the TaYlor-Schechter Genizah Collection (T-S Ar. 1A.136). - A Samaritan-Arabic manuscript fragment is analyzed to determine in which version of the Samaritan-Arabic family as represented in translations of the Pentateuch it belongs.

KeYwords: Samaritan Arabic; Pentateuch; Manuscript; Cairo Genizah; TaylorSchechter Collection.

${ }^{*}$ En el caso de J. P. Monferrer-Sala, el presente trabajo ha sido realizado en el marco del Proyecto de Investigación I+D FFI2011-25460/FILO: MANALEP-III «Manuscritos arameos y árabes de la Biblioteca Maronita de Alepo (Siria) y de la Fundación Georges et Mathilde Salem de Alepo (Siria). Catalogación y estudio», financiado por el Ministerio de Ciencia e Innovación (actual Ministerio de Economía y Competitividad).

** Deseo hacer constar mi gratitud a la Dra. María Ángeles Gallego (CSIC) y a la Dra. Esther Miriam Wagner (Taylor-Schechter Genizah Research Unit), que gentilmente pusieron a mi disposición el fragmento.

***ff1mosaj@uco.es 
En noviembre de 2007, en la sección de la página web de la Cambridge University Library conocida como «Fragment of the Month», el Dr. Friedrich Niessen daba noticia de uno de los tres textos samaritanos compuestos en escritura samaritana o árabe, de los que hasta el momento tenemos noticia, conservados en la Colección Taylor-Schechter de la Guenizá (Cambridge), en concreto el que corresponde a la signatura T-S Ar.1a.136', que contiene una muestra textual más de la cadena de especímenes manuscritos derivados de la versión que realizara Sa'adyah ha-Ga'ôn, distinta de las versiones utilizadas por otros autores judíos como Dunāš b. Labrāṭ o Yěhudah b. Bal'am, pues, como es conocido, la traducción que llevara a cabo Sa'adyah fue paulatinamente alterada por medio de readaptaciones, entre las que se encuentran las samaritanas, hasta alcanzar la forma que presenta el textus receptus de Abū Sa'īd, sustancialmente distinta del texto de Sa'adyah.

En esa noticia, junto a la reproducción fotográfica del rectum, el autor presentaba en una columna la transcripción del texto de dicho folio, añadiendo en columna paralela a la izquierda el texto correspondiente de la versión samaritana del Pentateuco con el objeto de poder facilitar la comparación con el texto hebreo por el lector interesado. Además, ofrecía unas notas sobre la traducción árabe indicando la literalidad de la misma, al tiempo que señalaba las diferencias existentes entre el texto hebreo samaritano y el hebreo masorético.

El fragmento, cuyo rectum describió el Dr. Niessen en la referencia que damos en $\mathrm{n}$. 1, consta de dos folios e incluye una traducción árabe de Ge 4,4-15. El texto exhibe una cuidada escritura nash̆ con vocalización esporádica, a la que se añade una línea en escritura samaritana mayúscula ${ }^{2}$ en la novena línea del rectum que corresponde al versículo 4,9a.

${ }^{1}$ Friedrich NIESSEN, en: http://www.lib.cam.ac.uk/Taylor-Schechter/fotm/november-2007/.

${ }^{2}$ Alan D. Crown, Samaritan Majuscule Palaeography: Eleventh to Twentieth Century (Manchester: John Rylands University Library, 1978). Sobre la escritura minúscula: Alan D. CRown, «Samaritan Minuscule Palaeography», Bulletin of the John Rylands Library of Manchester 63/2 (1981), 330-368. Acerca de la problemática que presentan los sistemas de escritura samaritana: Alan D. Crown, «Problems in Epigraphy and Palaeography: The Nature of the Evidence in Samaritan Sources», Bulletin of the John Rylands Library 62 (1979), 37-60. 
El estudio que realizara, como trabajo de tesis doctoral, de la versión samaritana del libro de Josué y la leyenda de Shobak ${ }^{3}$ había llevado al Dr. Niessen a interesarse por publicar, de forma paulatina, todos los materiales samaritanos o que representasen traducciones de originales samaritanos que llegasen a sus manos. Éste era uno de los varios casos que aguardaba el debido momento como consecuencia de la siempre apretada lista de tareas que tenía el Dr. Niessen. Sin embargo, el 16 de enero de 2009 nos dejaba tras una rápida y dolorosa enfermedad y todos sus proyectos quedaron en meras intenciones ${ }^{4}$.

Su esposa Elizabeth, en varias ocasiones, nos había manifestado a varios de sus amigos su interés en que retomásemos los trabajos que había iniciado su marido y que no había podido acabar debido a la enfermedad. Me consta que algunos compañeros se encuentran en esa tarea, la misma a la que yo entrego todo mi interés en este momento para terminar del mejor modo que pueda lo que nuestro recordado amigo inició hace años.

Como hemos indicado, el Dr. Niessen, junto con unas notas marco que acompañaban a la reproducción del fragmento transcribió el texto correspondiente al rectum, que nosotros reproducimos en este trabajo. A ello añadimos la edición del versum y la traducción de todo el texto, ofreciendo una descripción codicológica del soporte, un análisis paleográfico y lingüístico de las dieciocho líneas del texto árabe y de la línea en hebreo samaritano, concluyendo con un análisis filológico.

\section{EDICIÓN DEL FRAGMENTO}

Siguiendo el modelo adoptado por el Dr. Niessen en su nota, hemos procedido a editar el texto por líneas, diez en el rectum (9 en árabe y una en hebreo samaritano) y nueve en el versum, en este caso todas en árabe. A la izquierda del texto editado figura la traducción correspondiente, que

${ }^{3}$ Friedrich NIESSEN, Eine samaritanische Version des Buches Yehosu'a und die Sobak-Erzählung, «Texte und Studien zur Orientalistik» 12 (Hildesheim - Zurich - New York: Georg Olms, 2000).

${ }^{4}$ María Ángeles Gallego, «In memoriam Friedrich Niessen, ז (m. 16 enero de 2009)», Collectanea Christiana Orientalia 6 (2009), 433-436. 

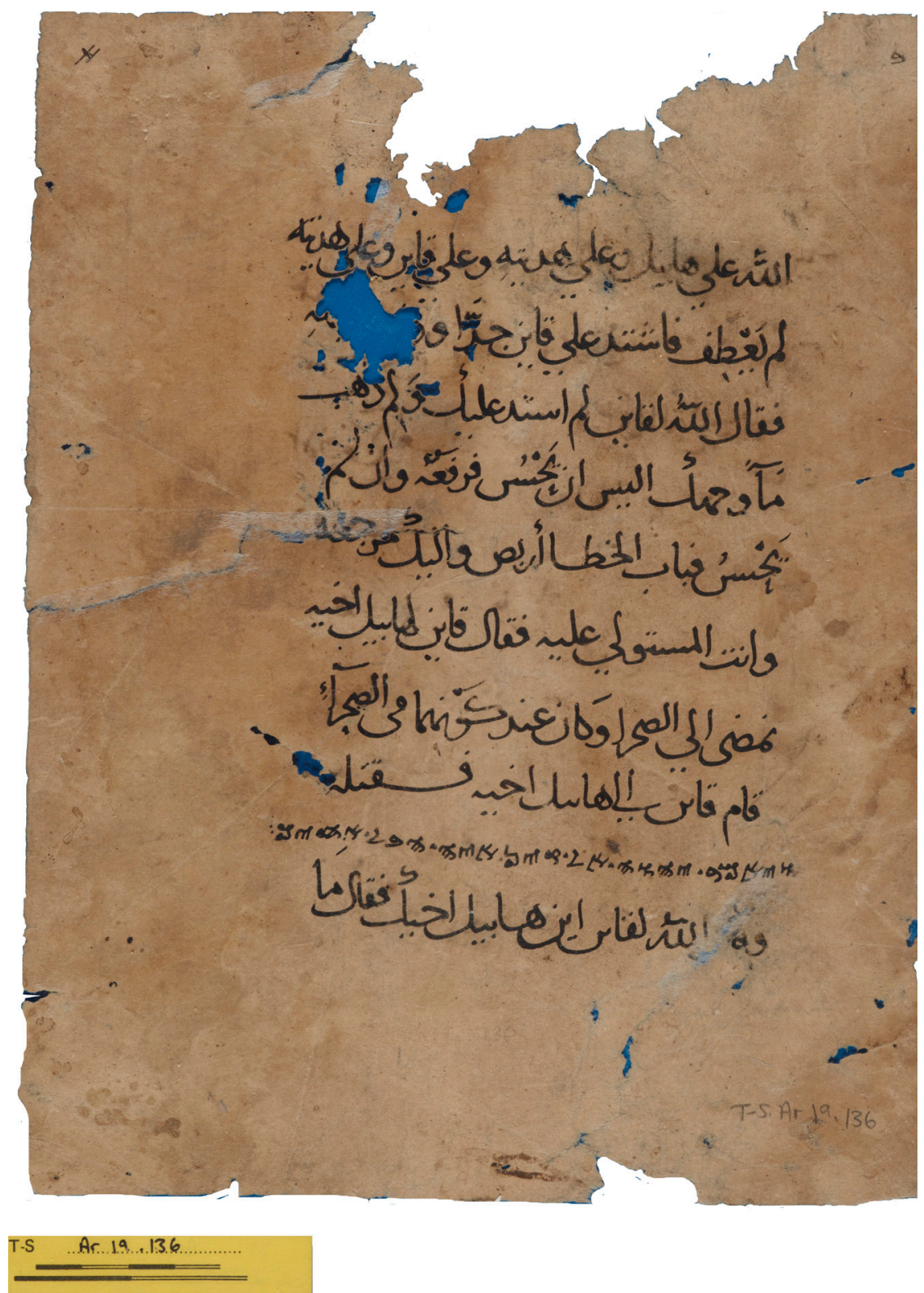

Fig. 1: CUL, Taylor-Schechter Genizah Collection, Ar.1a.136, rectum (Courtesy of the Syndics of Cambridge University Library). 
sigue el texto árabe literalmente. En el margen izquierdo indicamos para cada línea los versículos correspondientes al texto árabe y su traducción.

Rectum

versos traducción texto

\begin{tabular}{|c|c|c|c|}
\hline $4-5$ & $\begin{array}{l}\text { (...) Dios a Abel y a su } \\
\text { ofrenda, pero a Caín y a } \\
\text { su ofrenda }\end{array}$ & هديتهُ علي هابيل وعلي هديته وعلي قاين وعلي & 1 \\
\hline 5 & $\begin{array}{l}\text { no (los) miró con } \\
\text { agrado. Caín se enfadó } \\
\text { mucho y desapareció la } \\
\text { alegría de su rostro }\end{array}$ & 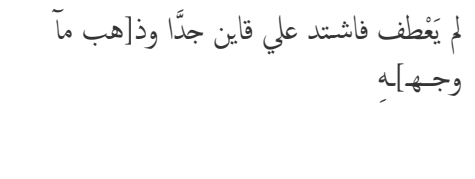 & 2 \\
\hline 6 & $\begin{array}{l}\text { y Dios dijo a Caín: ‘ ¿por } \\
\text { qué te has enfadado, por } \\
\text { qué ha desaparecido }\end{array}$ & فقال السُّ لقاين لم استد عليك وَلم ذهب & 3 \\
\hline $6-7$ & $\begin{array}{l}\text { la alegría de tu rostro? } \\
\text { Si se hace bien se es } \\
\text { enaltecido, pero si no }\end{array}$ & مآ وبحك اليس ان يَسْسُ فرفعَهُ وان لمج & 4 \\
\hline 7 & $\begin{array}{l}\text { se obra bien (tras) la } \\
\text { puerta el pecado acecha } \\
\text { y a ti volverá, }\end{array}$ & يَحَسُن فباب الخطا أربص واليك مرجعه & 5 \\
\hline $7-8$ & $\begin{array}{l}\text { pero tú te adueñarás } \\
\text { de él. Y Caín dijo a su } \\
\text { hermano Abel: }\end{array}$ & وانت المaستولي عليه فقال قاين لهابيل اخيه & 6 \\
\hline 8 & $\begin{array}{l}\text { ‘vamos al desierto'. Y } \\
\text { estando ambos en el } \\
\text { desierto }\end{array}$ & نغضى الي الصحرا وكان عند كَنها فن الصحرآي & 7 \\
\hline 8 & $\begin{array}{l}\text { se levantó Caín contra } \\
\text { su hermano y lo mató. }\end{array}$ & قام قاين الي هابيل اخيه فقتله & 8 \\
\hline 9 & $\begin{array}{l}\text { Y Dios dijo a Caín: } \\
\text { ¿ ¿dónde está tu hermano } \\
\text { Abel?’. Y él dijo: ‘no }\end{array}$ & 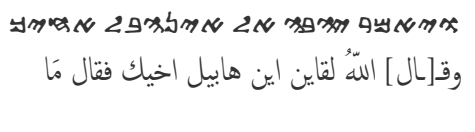 & $\begin{array}{r}9 \\
10\end{array}$ \\
\hline
\end{tabular}




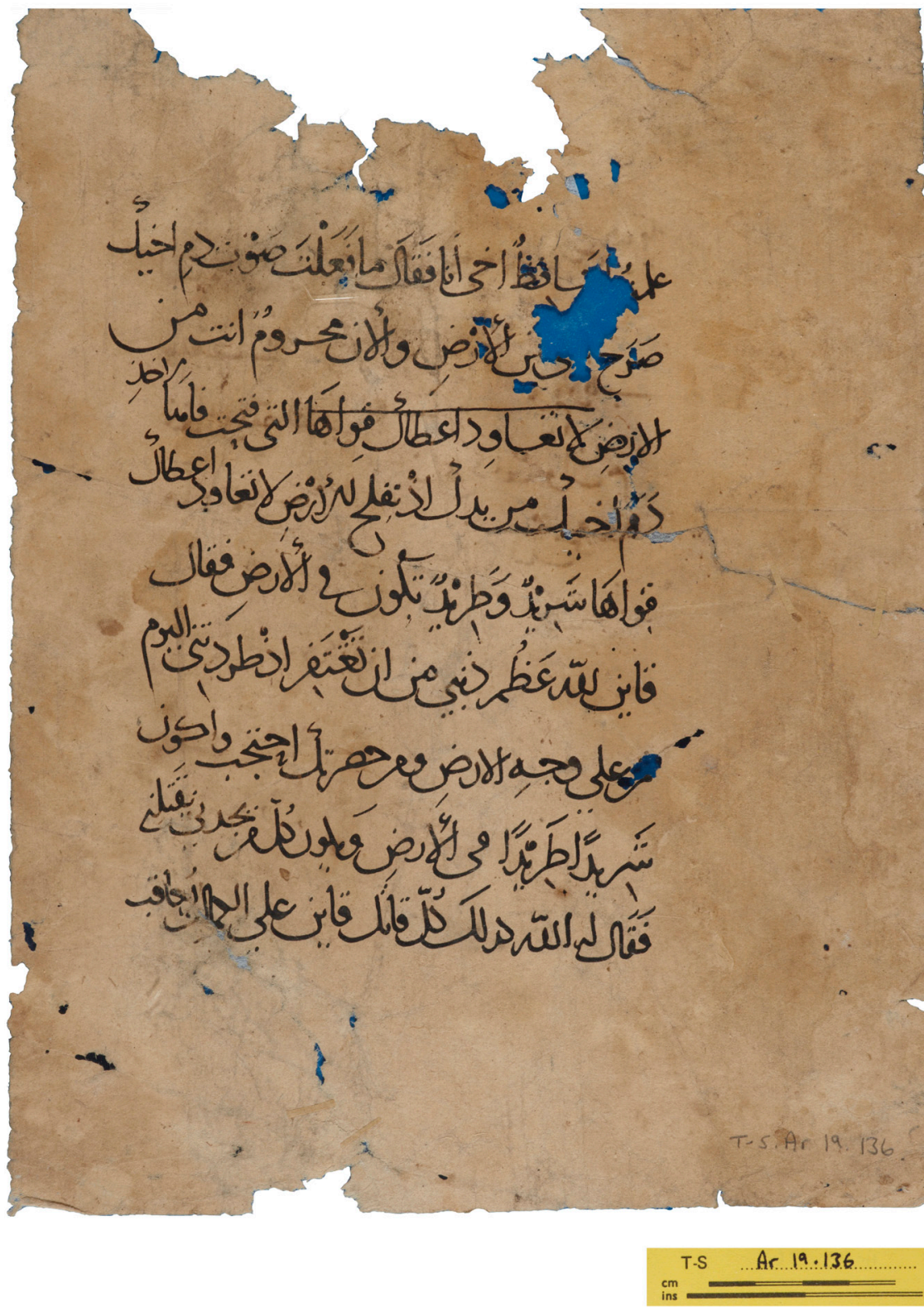

Fig. 2: CUL, Taylor-Schechter Genizah Collection, Ar.1a.136, versum (Courtesy of the Syndics of Cambridge University Library). 
Versum

versos

traducción

texto
9-10 se ¿Acaso soy el guardián de mi hermano? Y él le dijo: ¿qué has hecho? La voz de la sangre de tu hermano
1 صَوْت دم اخيك

10-11 clama hasta mí desde la tierra. Ahora, ¡maldito seas tú a causa de

11 la tierra, que abrió sus fauces para coger

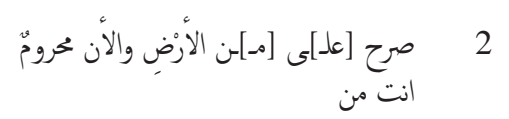

11-12 la sangre de tu hermano de tu mano. Cuando labres la tierra no volverá a darte
4 |عطاك

12-13 su fuerza; fugitivo y proscrito serás en la tierra'. Y dijo

$$
5
$$

13-14 Caín a Dios: 'terrible es mi pecado para ser perdonado. He aquí que me expulsas hoy
6 ق قاين للهّ عَظْم ذنبي من ان تغتفر اذْ طردتنى اليوم He aquí que me expulsas hoy

14 de la faz de la tierra; de tu presencia me esconderé y seré

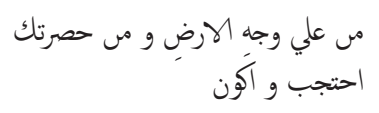
7 un fugitivo y un proscrito en la tierra y cualquiera que me encuentre me matará'.

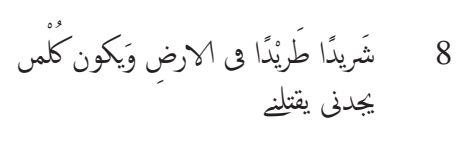

15 Por esto Dios le dijo: 'cualquiera que mate a فُقَال له اللهّ لدلك كلّ قاتل قاين علي الكمالِ 9 Caín será completamente castigado'. 


\section{DESCRIPCIÓN CODICOLÓGICA}

Como se puede apreciar en la reproducción fotográfica que incluimos en el presente trabajo, el fragmento, cuyo soporte es papel, presenta una rotura considerable en la parte central superior del rectum y del versum, así como tres desgarros que han sido reparados con pegamento: uno, el más diminuto en el margen superior, de escasa longitud y sin afectar al texto, pero que ha sido pegado para evitar la prolongación del desgarro de la hoja; los otros dos desgarros, en cambio, sí que afectan al texto.

El primero de estos dos desgarros se encuentra en la franja central de la hoja, en el margen izquierdo del rectum (derecho del versum) que afecta a la última palabra (مرجعة) de la línea $5^{\text {a }}$ de éste y a las dos primeras palabras (دَم اخيك) de la línea $4^{a}$ del versum. El segundo desgarro, éste en la parte inferior derecha que arranca desde el mismo borde de la hoja alcanza a la segunda palabra de la última línea $\left(10^{\mathrm{a}}\right)$ del rectum causando la desaparición del segundo grafema de la forma verbal قال, cuya lām es restituida en la edición. Asimismo, ese desgarro afecta a la penúltima palabra (الكال) de la última línea $\left(10^{a}\right)$ del versum, cuya lectura sin embargo no se ha visto afectada.

Los dos folios presentan, además, otros daños en la hoja de diversa índole. El más llamativo es el orificio que afecta a la línea $2^{\mathrm{a}}$ del rectum, concretamente a las tres últimas palabras (ذهب مآونجه), que han sido reconstruidas en la edición con total fiabilidad dado que la construcción ha sido reproducida exactamente a caballo entre las líneas $3^{\mathrm{a}}$ y $4^{\mathrm{a}}$. Ese mismo orificio, en el versum, afecta a las líneas $1^{\mathrm{a}}$ y $2^{\mathrm{a}}$ : las dos primeras palabras de la línea $1^{a}$ (عَمتُ احَافع) y la segunda y tercera (على من) de la 2a línea. El resto de orificios que presenta la hoja, más de una veintena, se encuentran aquí y allá, pero dadas sus pequeñas dimensiones y su localización fuera del texto no afectan a la lectura de éste.

Finalmente, la línea $3^{\mathrm{a}}$ del versum exhibe un lapsus oculi debido a que el copista ha confundido la línea de lectura y ha copiado una serie de cuatro palabras como correspondientes al versículo 11, cuando en realidad pertenecen a un versículo posterior, el 12, del que se ha apercibido

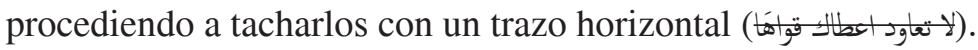




\section{ANÁLISIS PALEOGRÁFICO Y LINGÜÍSTICO}

Como hemos señalado más arriba, el tipo grafológico utilizado por el copista es el sistema nashī. La factura de la escritura es excelente, con una cuidada y pulcra definición de los caracteres cuya morfología presenta una realización redondeada en las consonantes finales. Frente a un buen número de casos producidos por copistas árabes cristianos, que exhiben abundantes deficiencias en la realización de los grafemas y sus correspondientes diacríticos 5 , el presente texto ofrece una realización correcta del ductus consonántico, con una serie de peculiaridades en la realización de los diacríticos a las que nos referiremos enseguida. Asimismo, los dos folios presentan una serie de fenómenos linguiísticos propios del registro lingüístico conocido como «árabe medio», que en este caso hay que encuadrar en la variedad del árabe samaritano en su doble realidad hablada y escrita ${ }^{6}$.

Las peculiaridades en la realización de los diacríticos a las que acabamos de referirnos se deben a dos causas, que no en todos los casos hay que identificar con fenómenos fonológicos propios de la realización del árabe samaritano en su registro medio:

a) las deficiencias ortográficas u omisión de diacríticos, llegando el copista a suplir el trazo final del diacrítico de la ğìm mediante el trazo final de la wāw en el caso de wağhika (4r).

b) a las interferencias de fenómenos lingüísticos procedentes del registro neoárabe.

En el caso de a) las diversas deficiencias ortográficas que exhibe el texto son las siguientes:

- consonantes con ausencia de diacríticos en el nivel suprasegmental:

/f/: $f i\left(7^{\mathrm{r}}, 5^{\mathrm{v}}, 8^{\mathrm{v}}\right)$

/n/: yahsuna $\left(4^{\mathrm{r}}, 5^{\mathrm{r}}\right), \min \left(7^{\mathrm{v}}\right)$

${ }^{5}$ Cf. para el caso del árabe cristiano, Joshua Blau, A Grammar of Christian Arabic. Based Mainly on South-Palestinian Texts from the First Millenium [en adelante, GCA], 3 vols. (Louvain: Secrétariat du CorpusSCO, 1966-67), I, 122-125 §§ 25-26.3.2.

${ }^{6}$ Moshe Florentin, Late Samaritan Hebrew: A Linguistic Analysis of its Different Types (Leiden - Boston: Brill, 2005), 23-25. 
- consonantes con ausencia de diacríticos en el nivel infrasegmental:

/b/ Hābül ( $\left.8^{\mathrm{r}}\right)$

/ğ/: wağhika $\left(4^{\mathrm{r}}\right)$

/y/: Qāyin <Q $\bar{a}^{\prime}$ in $\left(8^{\mathrm{r}}, 10^{\mathrm{r}}, 6^{\mathrm{v}}, 9^{\mathrm{v}}\right)$, Hābīl $\left(8^{\mathrm{r}}\right), f_{\imath}\left(5^{\mathrm{v}}, 8^{\mathrm{v}}\right)$, taradtan̄̄ $\left(6^{\mathrm{v}}\right)$, yaqtulanī $\left(8^{\mathrm{v}}\right)$

En un caso hay duplicación de diacríticos debido a la acumulación de diacríticos en el nivel suprasegmental: se trata de la gayn del imperfectivo subjuntivo tagtafir < tag்tafira $\left(6^{v}\right)$. Hay que añadir, además, cuatro rasgos más que presenta el copista: en primer lugar la realización del adorno de la $k \bar{a} f$ en forma de $k \bar{a} f$ diminuta, pero que no aparece inserto en el cuerpo del grafema, sino desplazado a la parte superior de ésta $\left(3^{\mathrm{r}}, 4^{\mathrm{r}}, 5^{\mathrm{r}}, 10^{\mathrm{r}}, 1^{\mathrm{v}}, 3^{\mathrm{v}}, 4^{\mathrm{v} / \mathrm{bis}}, 7^{\mathrm{v}}\right)$, cuya función no parece ser otra que la de servir de rasgo discriminatorio con respecto a la lām, que el copista realiza de forma semejante. En segundo la adición debajo de la $h \bar{a}$ ' medial de una $h \bar{a}^{\prime}$ final diminuta $\left(4^{\mathrm{r}}, 5^{\mathrm{r}}, 3^{\mathrm{v}}, 7^{\mathrm{v}}\right)$. En tercer lugar la realización de la hamzah en tres ocasiones: sobre la alif de la forma causativa 'arbașa $\left(5^{\mathrm{r}}\right)$, que es obviamente un rasgo clasicista que desea exhibir el copista, tras la alif tawīlah del pluralis fractus șahrā' $\left(7^{\mathrm{r}}\right)$, concretamente en el segundo de los casos en que aparece el término, y sobre la alif de $\operatorname{al}$ - $\operatorname{ard}\left(2^{\mathrm{v}}, 4^{\mathrm{v}}, 5^{\mathrm{v}}, 8^{\mathrm{v}}\right)$. En cuarto lugar, la realización de la $h \bar{a}$ ' en función de forma pronominal sufijada de 3 . $^{\mathrm{a}} \mathrm{p}$. sing. adopta en algunas ocasiones una morfología distinta a la $h \bar{a}$ ' de la $t \bar{a}$ ' marbūtah carente de diacríticos (cf. $\left.1^{\mathrm{r}}\right)$ o a otros casos de $h \bar{a}$ ' en función de forma pronominal sufijada de $3 .^{\mathrm{a}} \mathrm{p}$. $\operatorname{sing}$. $\left(1^{\mathrm{r}}, 4^{\mathrm{r}}, 7^{\mathrm{v}}\right)$ : rafa'ahu $\left(4^{\mathrm{r}}\right)$, 'alayhi $\left(6^{\mathrm{r}}\right)$, ahīhi $\left(6^{\mathrm{r}}, 8^{\mathrm{r}}\right)$, qatalahu $\left(8^{\mathrm{r}}\right)$, li-l-Lah $<$ li-l-Lāh $\left(6^{\mathrm{v}}\right)$, lahu $\left(9^{\mathrm{v}}\right)$, Allah $<$ Allāh $\left(9^{\mathrm{v}}\right)$.

En el uso de las preposiciones 'alà e ilà la alif maqșūrah ${ }^{7}$ adopta los dos diacríticos de la $y \bar{a}$ ', con el consabido cambio $/ \overline{\mathrm{e}} /</ \overline{\mathrm{a}} /$ : $^{\prime} a l \bar{e}$ (*'al $\left.\bar{\imath}\right)$

${ }^{7}$ Blau, GCA, 81-83 (\$§ 10.1-10.3); Simon Hopkins, Studies in the Grammar of Early Arabic. Based upon Papyri Datable to Before A.H. 300/A.D. 912 (Oxford: Oxford University Press, 1984), 14-16 (§ 12); Per Å. Bengtsson, Two Arabic Versions of the Book of Ruth. Text edition and language (Lund: Lund University Press, 1995), 104 (§ 3.2.3); Bengt Knutsson, Studies in the Text and Language of three Syriac-Arabic Versions of the Book of Judicum with Special Reference to the Middle Arabic Elements. IntroductionLinguistic Notes-Texts (Leiden: E. J. Brill, 1974), 58-59. 
< 'alà $\left(1^{\mathrm{r}: 3}, 2^{\mathrm{r}}, 7^{\mathrm{v}}, 9^{\mathrm{v}}\right)$, cf. sin embargo 'alà en $\left.2^{\mathrm{v}}\right)$, ilè $(* i l \bar{\imath})<$ ilà $\left(7^{\mathrm{r}}, 8^{\mathrm{r}}\right)$. El fenómeno de la alif maqșūrah en lugar de la yā' se aprecia también en los casos siguientes: fì $\left(7^{\mathrm{r}}\right)$, banà $<$ banī $\left(14^{\mathrm{r}}, 1^{\mathrm{v}}\right)$, nam $<$ 'ahī $\left(1^{\mathrm{v}}\right)$, *alatà < allatī $\left(3^{\mathrm{v}}\right)$, *yaqtulanà < yaqtulanī $\left(8^{\mathrm{v}}\right)$. Con todo, la posibilidad de que el fenómeno de la alif maqșūrah con diacríticos responda a un caso de imālah debe ser combinado con una segunda posibilidad, a saber: que se trate de un mero fenómeno ortográfico como así lo justifican los usos de $y \bar{a}$ ' sin diacríticos.

En el nivel suprasegmental, el uso de la šaddah o tašdīd $d^{8}$ es prácticamente inexistente en todo el texto, a excepción del teóforo Allāh, que el copista escribe con scriptio defectiva: Allahu $<$ Allāhu $\left(1^{\mathrm{r}}, 3^{\mathrm{r}}, 10^{\mathrm{r}}, 9^{\mathrm{v}}\right)$, $l i-l-L a h<l i-l-L a \bar{h}\left(6^{v}\right)$. El conocido rasgo sociolectal de la escritura Alah carente de $\check{s} a d d a h($ Alah $<$ Allāh) que registran los textos árabes cristianos debido al interés de los autores árabes cristianos de diferenciarlo del uso morfológico que hacen los autores musulmanes de la voz Allāh no se da en nuestro texto, que realiza la šaddah aunque en scriptio defectiva: Allahu < Allāhu $\left(1^{\mathrm{r}}, 3^{\mathrm{r}}, 10^{\mathrm{r}}\right)$. Contamos además con otros casos de geminación en ğidd ${ }^{a n}\left(2^{\mathrm{r}}\right)$, kulluman $\left(8^{\mathrm{v}}\right)$, kull $\left(9^{\mathrm{v}}\right)$.

La alif maddah ${ }^{9}$ es realizada en $m \bar{a}<m \bar{a}^{\prime}\left(4^{\mathrm{r}}\right)$. Hay un caso de hipocorrección al sustituir la alif madda por hamzah 'alà kursī alif: al-'an < al-ān $\left(2^{\mathrm{v}}\right)$. También la alif waṣlah es objeto de omisión, dando lugar a prolongación vocálica $(/ \bar{a} /)$ cuando va precedida de partícula preclítica: fāštada $<$ fa'-ištadda $\left(2^{\mathrm{r}}\right)$.

En el nivel vocálico, las vocales largas han sido indicadas correctamente mediante las matres lectionis correspondientes sin que figuren expresamente los diacríticos de las mociones, con la excepción de los nombres $\check{s} a r \bar{i} d^{u n}\left(5^{\mathrm{v}}\right)$ y $\operatorname{tarī}^{u n}\left(5^{\mathrm{v}}\right)$ y el imperfectivo yakūn < yakūnu $\left(5^{\mathrm{v}}\right)$. A su vez, en el caso de las vocales breves hay un uso no sistematizado de las mociones, con la siguiente serie de excepciones que notamos en redondilla y por categorías gramaticales:

${ }^{8}$ BLAu, GCA, 122-125 (§§ 26.1-26.3.2); Hopkins, Studies, 49 (§ 48); Federico CorriEnte, A Grammatical Sketch of the Spanish Arabic Dialect Bundle (Madrid: Instituto Hispano-Árabe de Cultura, 1977), 66-67 (§ 3.2.1-3.2.2).

${ }^{9}$ Hopkins, Studies, 49 (§ 49i). 
a) Nombres: $m \bar{a}<m \bar{a}^{\prime}\left(4^{\mathrm{r}}\right)$, con fathah ante alif maddah; kawn $\left(7^{\mathrm{r}}\right)$,

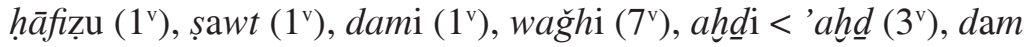
$\left(4^{\mathrm{v}}\right), \operatorname{arḍi}<{ }^{\prime} \operatorname{ard}\left(4^{\mathrm{v}}, 5^{\mathrm{v}}, 7^{\mathrm{v}}, 8^{\mathrm{v}}\right)$, šarīd ${ }^{u n}\left(5^{\mathrm{v}}\right)$, țarīd $d^{u n}\left(5^{\mathrm{v}}\right)$, ' $\mathrm{azm}\left(6^{\mathrm{v}}\right)$, $\check{s}$ arī $d^{\text {an }}\left(8^{v}\right), \operatorname{tar} \overline{1} d^{\text {an }}\left(8^{v}\right)$. Asimismo, hay que añadir a esta nómina la realización del caso nominativo en el teóforo: Allahu $<$ Allāhu $\left(1^{\mathrm{r}}, 3^{\mathrm{r}}\right)$.

b) pronombres:

1. 1. ${ }^{\mathrm{a}}$ p. sing: anā $<$ 'anā $\left(1^{\mathrm{v}}\right)$.

2. indefinidos: kulluman $\left(8^{\mathrm{v}}\right)$, kull $\left(9^{\mathrm{v}}\right)$.

3. sufijos pronominales:

1. 3. ${ }^{\mathrm{a}}$ p. sing.: hadiyatihi < hadiyyatihi $(1 r)$; wağhihi $\left(2^{\mathrm{r}}\right)$.

2. 3. ${ }^{\mathrm{a}}$ f. sing.: quwāhā $\left(3^{\mathrm{v}}, 4^{\mathrm{v}}\right), f \bar{a} h \overline{\mathrm{a}}\left(3^{\mathrm{v}}\right)$.

3. formas verbales:

1. perfectivas: $\operatorname{rafa}^{\prime} a\left(4^{\mathrm{r}}\right), q \overline{\mathrm{a}} l \overline{\mathrm{a}}\left(1^{\mathrm{v}}\right)$, fa'alta $\left(1^{\mathrm{v}}\right)$, șaraha $\left(2^{\mathrm{v}}\right)$, qāla $\left(9^{v}\right)$.

2. imperfectivas: yaqtulanī (8v), yu 'āqib < yu 'āqibu (9v).

2.1. apocopado ya 'tif $\left(2^{\mathrm{r}}\right) ;$ yahsuna $\left(5^{\mathrm{r}}\right)$.

2.2. subjuntivo yahsuna $\left(4^{\mathrm{r}}\right)$, taġtafir $<$ tag்tafira $\left(6^{\mathrm{v}}\right)$.

4. partículas:

1 conjunciones copulativas: $w a-\left(3^{r}\right), f a-\left(9^{v}\right)$.

2 adverbio de negación $m \bar{a}\left(10^{\mathrm{r}}\right)$.

3 preposición $l i$-: $l i$-ahd $\underline{d}<l i$ ahd $\underline{d}\left(3^{v}\right)$.

4 conjunción $i \underline{d}<{ }^{\prime} i \underline{d}\left(6^{v}\right)$.

La ausencia de vocal o sukūn ha sido indicada en ya tif $\left(2^{\mathrm{r}}\right)$, id

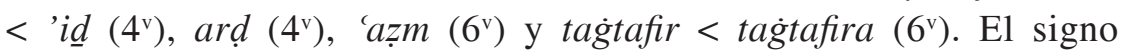
suprasegmental del sukūn indica valor de mater lectionis de $y \bar{a}$ ' en los casos de $\check{s} \operatorname{ar} d^{u n}\left(5^{\mathrm{v}}\right)$ y $\operatorname{tarīd}^{a n}\left(5^{\mathrm{v}}, 8^{\mathrm{v}}\right)$. En el caso de las vocales muy breves o tanwīn éstas son mocionadas por el copista en el participio pasivo mahrūmm ${ }^{u n}\left(2^{\mathrm{v}}\right)$ y en los nombres šarīd $d^{u n}\left(5^{\mathrm{v}}\right)$, $\operatorname{tar}_{\bar{i}} d^{u n}\left(5^{\mathrm{v}}\right)$ y sus correspondientes formas acusativas šarīd ${ }^{a n}(8 \mathrm{v})$ y $\operatorname{tar}^{-} d^{a n}(8 \mathrm{v})$, aunque en ocasiones ha dado lugar a deficiencias al realizarlas: es el caso de ğidd ${ }^{a n}\left(2^{\mathrm{r}}\right)$, que es realizado con un solo signo en lugar de los dos correspondientes. 
El copista recurre a la scriptio plena en casos como Hābìl $\left(1^{\mathrm{r}}, 6^{\mathrm{r}}, 8^{\mathrm{r}}, 10^{\mathrm{r}}\right)$ y $Q \bar{a} y i n<Q \bar{a}{ }^{\prime}{ }^{\prime}{ }^{\prime}\left(1^{\mathrm{r}}, 2^{\mathrm{r}}, 3^{\mathrm{r}}, 6^{\mathrm{r}}, 8^{\mathrm{r}}, 10^{\mathrm{r}}, 6^{\mathrm{v}}, 9^{\mathrm{v}}\right)$, en tanto que hay presencia de scriptio defectiva en la partícula interrogativa lima $\left(3^{\mathrm{r}}\right)$ y en la deixis dalik $<\underline{d} \bar{a} l i k a\left(9^{v}\right)$. Cabe finalizar señalando que desde el punto de vista paleográfico destaca la realización de la kasrah con direccionalidad invertida, i.e. con trazo cuya dirección va de izquierda a derecha y sentido cuasi vertical con ligera inclinación a la derecha: $-\left(5^{v}, 6^{v}, 8^{v}\right)$.

En el nivel consonántico ${ }^{10}$, frente al uso estable que exhibe el fonema $h a m z^{11}$ en árabe clásico, en neoárabe, por el contrario, sólo es realizado en posición inicial aunque sin evidencia ortográfica, aun cuando su función fonémica independiente se haya perdido desde los primeros momen$\operatorname{tos}^{12}$. Nuestro texto omite el grafema /'/ en todas las posiciones, lo cual evidencia que la pausa articulada de la /'/ no era perceptible en el registro utilizado por el autor o el copista, exhibiendo de este modo la pronunciación coloquial de esta consonante.

a) Inicial: $a<$ 'a $\left(4^{\mathrm{r}}\right)$, an < 'an $\left(4^{\mathrm{r}}, 6^{\mathrm{v}}\right)$, in < 'in (4r), ilayk < 'ilayka (5r), ant $<$ 'anta $\left(6^{\mathrm{r}}, 2^{\mathrm{v}}\right)$, ahīhi $<$ 'ah̄ihi $\left(6^{\mathrm{r}}, 8^{\mathrm{r}}\right)$, ayn $<$ 'ayna $\left(10^{\mathrm{r}}\right), a<$ 'a

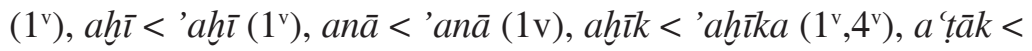
'a țāka $\left(3^{v}, 4^{v}\right), \underline{i d}<$ 'i $\underline{d}\left(4^{v}\right), i \underline{d}<{ }^{\prime} i \underline{d}\left(6^{v}\right)$, akūn $<$ 'akūnu $\left(7^{v}\right)$.

b) Medial: Qāyin < Q $\bar{a}^{\prime}$ in $\left(1^{\mathrm{r}}, 2^{\mathrm{r}}, 3^{\mathrm{r}}, 6^{\mathrm{r}}, 8^{\mathrm{r}}, 10^{\mathrm{r}}, 6^{\mathrm{v}}, 9^{\mathrm{v}}\right)$, al-ard < al-'ard $\left(3^{\mathrm{v}}, 4^{\mathrm{v}}, 8^{\mathrm{v}}\right), l i-a \underline{h} \underline{d}<l i$-ahd $\underline{d}\left(3^{\mathrm{v}}\right)$.

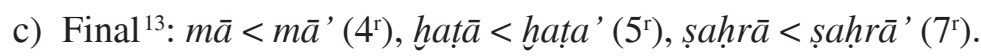

${ }^{10}$ Blau, GCA, 83-121 (\$§ 11-24.4); Jean Cantineau, Études de linguistique arabe. Mémorial Jean Cantineau (Paris: Klincksieck, 1960), 13-88; Bengtsson, Two Arabic Versions, 108-128 (§§ 3.2.5-3.2.16); KNuTsson, Studies, págs. 59-112; CoRrIEnTE, Sketch, 31-60 (\$§ 2.1.1-2.28.7).

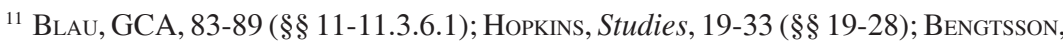
Studies, 108-114 (\$§ 3.2.5-3.2.5.3); KNUTsson, Studies, 59-78; CorrIENTE, Sketch, 58-60 (§§ 2.28.1-2.28.7).

${ }^{12}$ BLAU, GCA, 83-84 (\$§ 11-11.1).

${ }^{13}$ Joshua BLAU, «Middle and Old Arabic Material for the History of Stress in Arabic», Bulletin of the School of Oriental and African Studies 35 (1972), 476-484. 
Aunque debemos precisar que no todos los fenómenos son el producto de cambios fonéticos, los cambios consonánticos que presenta el texto son los siguientes:

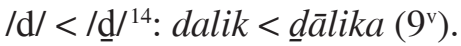

$/ \mathrm{s} /</ \check{\mathrm{S}} /{ }^{15}:$ istada $<$ ištadda $\left(3^{\mathrm{r}}\right)$.

/ṣ/ < / $/{ }^{16}:$ haṣaratik < hạa daratika $\left(7^{\mathrm{v}}\right)$.

En el ámbito onomástico, los dos únicos nombres propios que documenta el texto representan arabizaciones a partir de formas antroponímicas hebreas:

Hābīl $\left(1^{\mathrm{r}}, 6^{\mathrm{r}}, 8^{\mathrm{r}}, 10^{\mathrm{r}}\right)$ : del hebreo הֶבֶלתהֶ, aunque todo indica que no directamente de la forma samaritana $\mathbf{2} \boldsymbol{g} \boldsymbol{x}$, sino con interferencia de la siriaca 1 ×ُ

Qäyin <Q $\bar{a}^{\prime}$ in $\left(1^{\mathrm{r}}, 2^{\mathrm{r}}, 3^{\mathrm{r}}, 6^{\mathrm{r}}, 8^{\mathrm{r}}, 10^{\mathrm{r}}, 6^{\mathrm{v}}, 9 \mathrm{v}\right)$ : del hebreo per, que también en este caso no representa una adaptación del samaritano $\downarrow \gg \triangleright$, sino de la forma siriaca مُمْم

Y algo parecido cabe decir de las formas onomásticas de los dos topónimos que figuran en el fragmento, con la diferencia de que en este caso no son formas hebreas, sino adaptaciones procedentes de otras lenguas:

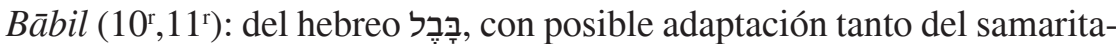
no 2 S

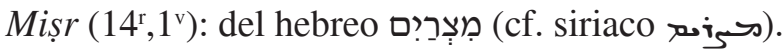

${ }^{14}$ Joshua Blau, The Emergence and Linguistic Background of Judaeo-Arabic. A Study of the Origins of Middle Arabic (Jerusalem: Ben Zvi Institute, 1981), 76, 227, 231. Cf. Blau, GCA, 108 ( $\$ 16.2$ ); Knutsson, Studies, 98-100 (cf. 82-94 and 122); Bengtsson, Two Arabic Versions, 116 ( $\$$ 3.2.6); Bernhard Levin, Die griechischarabische Evangelien-Übersetzung. Vat Borg. Ar. 95 und Ber orient. Oct. 1108 (Uppsala, 1938), 19; Corriente, Sketch, 45 (§ 2.13.2). Véase además F. Corriente, «A Survey of Spirantization in Semitics and Arabic Phonetics», JQR 60 (1969), 160-162. Cf. Juan Pedro Monferrer-Sala, «Mutatio nominum. Onomástica griega en transcripción árabe», Collectanea Cristiana Orientalia 4 (2007), 83.

${ }^{15}$ Blau, The Emergence, 229. Cf. Blau, GCA, I, 110-111 (§ 17.2).

${ }^{16}$ BLAU, The Emergence, 28, 77. 


\section{ANÁLISIS FILOLÓGICO}

Como es conocido, el texto del Pentateuco samaritano (PS) ${ }^{17}$ fue fijado en un tipo grafológico de hebreo antiguo ${ }^{18}$ (early Hebrew) que ha sido conservado por la comunidad samaritana a lo largo de los siglos. Entre los varios rasgos interesantes que ofrece PS se encuentra una importante serie de elementos ideológicos no sectarios muy similares a los denominados materiales pre-samaritanos encontrados en Qumrán ${ }^{19}$. Por lo demás, de la proyección del episodio narrado en Ge 4,1-16 da cuenta la proliferación de tradiciones textuales en griego y en siriaco que corrieron durante la Tardo-antigüedad y la Edad Media ${ }^{20}$.

La traducción árabe del fragmento objeto de estudio forma parte de uno de los cinco grandes textos-tipo, entre los que se encuentra la revisión del Pentateuco samaritano (RASPS) realizada por Abū $\mathrm{Sa}$ '̄̄ en en el siglo XIII ${ }^{21}$. Esta revisión-adaptación árabe llevada a cabo con el objetivo, entre otros, de eliminar los sa'adyanismos que transmitían algunas traducciones árabes que circulaban entre las comunidades samaritanas ${ }^{22}$, fue

[El Pentateuco: la version samaritana y la version masorética], ed. and annot. by Abraham TAL and Moshe FLorentin (Tel Aviv: The Haim Rubin Tel Aviv University Press, 2010). 161.

${ }^{18}$ Angel SÁEnz-Badillos, Historia de la lengua hebrea (Sabadell: Ausa, 1988), 149-

${ }^{19}$ Esther EsHel - Hanan EsHel, «Dating the Samaritan Pentateuch's compilation in light of the Qumran Biblical Scrolls», en Emanuel. Studies in Hebrew Bible, Septuagint, and Dead Sea Scrolls in Honor of Emanuel Tov, ed. Shalom M. PAul et al. (Leiden: Brill, 2003), 219-221.

${ }^{20}$ J. B. Glenthøנ, Cain and Abel in Syriac and Greek Writers $-4^{\text {th }}-6^{\text {th }}$ Centuries (Louvain: Peeters, 1997); A. Su-Min RI, Commentaire de la Caverne des Trésors. Étude sur l'histoire du texte et de ses sources (Louvain: Peeters, 2000), 185-190; Lourdes Bonhome Pulido, «Ibn al-Ṭayyib y su tafsìr al relato de Caín y Abel en el Firdaws alnașrāniyyah», en Legendaria medievalia. En honor de Concepción Castillo Castillo, eds. Raif G. Khoury, J. P. Monferrer-Sala, Ma J. Viguera Molins (Córdoba: El Almendro, 2011), 433-448.

${ }^{21}$ H. Shehadeh, The Arabic Translation of the Samaritan Pentateuch (Jerusalem: Israel Academy of Sciences and Humanities, 1989 y 2002).

${ }^{22}$ Alan D. CRown, «Samaritan literature and its manuscripts», Bulletin of the John Rylands Library 76 (1994), 21-50: 38-39. Cf. Ronny VollandT, The Transmission of the Judaeo-Arabic Pentateuch Translation of Rav Saadiah Gaon in Arabic letters: A 
el fruto del proceso de adaptación que condujo al textus receptus de Abū $\mathrm{Sa}^{\mathrm{e}} \overline{1} \mathrm{~d}$ que conocemos en la actualidad ${ }^{23}$.

A continuación ofrecemos un análisis comparativo de la versión árabe con otras versiones del Pentateuco con el objeto de precisar ante qué tipo de texto nos encontramos. Por motivos de funcionalidad comparativa, los pasajes correspondientes al Pentateuco samaritano (PS) han sido transliterados en caracteres hebreos ${ }^{24}$. Asimismo, hemos recurrido a los targûmîm, tanto los judíos (TO, TN) ${ }^{25}$ como lo fragmentos arameos del Targum samaritano (TS) ${ }^{26}$, a versiones árabes cristianas realizadas a partir de Vorlagen distintas ${ }^{27}$, así como el Comentario (tafsīr) del autor siriaco oriental Ibn al-Ṭayyib ${ }^{28}$.

Como trataremos de mostrar en el análisis versicular, el texto árabe samaritano del fragmento (FAS), a excepción de dos casos, presenta una versión que se adecúa literalmente al texto del Pentateuco samaritano, aunque al mismo tiempo exhibe lecturas sa' adyanas o recoge interferencias procedentes de la versión de Sa'adyah, que en ningún caso ha de ser

Case of Textual Diffusion (Jerusalem: The Hebrew University, 2007; MA dissert., dir. S. Hopkins), 27-29.

${ }^{23}$ Shenadeh, The Arabic Translation of the Samaritan Pentateuch, I, 158-164, 273-335. Cf. Paul E. KAHLE, Die arabischen Bibelübersetzungen. Text mit Glossar und Literaturübersicht (Leipzig: J. C. Hinrichs'sche Buchhandlung, 1904), X-XIII; también Paul E. Kahle, The Cairo Geniza (Oxford: Oxford University Press, 1959), 54-55 y Samir Khalil SAMIR, «Édition de l'Untersuchungen zu Saadjas arabischer Pentateuchübersetzung de Max Katten», Parole de l'Orient 32 (2007), 34-36 et passim.

${ }^{24}$ Seguimos la edición crítica de August GaLl, Der hebräische Pentateuch der Samaritaner (Giessen: Töpelmann, 1918), 5-6.

${ }^{25}$ Targum Onkelos (TO) in The Bible in Aramaic. Based on old manuscripts and printed texts, edited by Alexander SPERBER (Leiden - Boston: Brill, 2004), 6 (= 1233); Targum Neophyti (TN) in Neophyti 1. Targum palestinense ms de la Biblioteca Vaticana. Génesis, ed. Alejandro Dí́zZ MAcho (Madrid - Barcelona: CSIC, 1968), 20-25.

${ }^{26}$ Cf. Adolf BRÜLL (ed.), Das samaritanische Targum zum Pentateuch. Herausgegeben [und] kritische Studien über Oxforder Manuscript-Fragmente, 3 vols. (Frankfurt a. M.: Wilhelm Erras, 1875), 4-5.

${ }^{27}$ Paul de Lagarde, Materialien zur Kritik und Geschichte des Pentateuchs, 2 vols. (Leipzig: B. G. Teubner, 1867), I, 48-55; II, 5.

${ }^{28}$ IBn AL-ṬAYyib, Commentaire sur la Genèse, ed. y trad. J. C. J. SANDERs, 2 vols. (Louvain: Secrétariat du CorpusSCO, 1967), I, 39-43 (texto árabe). 
minusvalorada ${ }^{29}$. El hecho de que FAS incluya elementos sa'adyanos y al mismo tiempo siga literalmente a PS no debe causar extrañeza, dado que la versión de Sa'adyah de Ge 4:4-15 por lo general sigue literalmente el texto hebreo masorético (THM), y éste y PS mantienen el mismo orden sintagmático. Es lógico, pues, que haya una correspondencia en el orden de las palabras entre la versión de Sa'adyah, FAS y PS. De hecho, THM y PS exhiben ocho diferencias en el pasaje aquí estudiado que no representan variantes textuales ${ }^{30}$.

Junto a lo que acabamos de exponer, tampoco hay que dejar de lado el reciente planteamiento de Schwarb, con el que retoma el interesante tema de la influencia que pudieron ejercer las versiones caraítas del Pentateuco en la traducción árabe del PS ${ }^{31}$, posibilidad en la que incidió hace unos años Polliack y a la que prestó atención Loewenstamm hace casi medio siglo ${ }^{32}$.

\section{ANÁLISIS VERSICULAR}

$$
\begin{aligned}
& \text { versos ArS PS } \\
& \text { יהוה אל הבל ואל מנחתו ואל קין ואל اللهُ علي هابيل وعلي هديته وعلي قاين 5-4 } \\
& \text { מנחתו و פרלي هديته }
\end{aligned}
$$

La traducción árabe sigue literalmente el texto samaritano. Únicamente el término hadiyyah ('ofrenda') plantea alguna duda: no de que represente la traducción literal de la palabra correspondiente en hebreo samaritano, como de hecho lo es, sino cuál sea su referente textual exacto, pues tanto la

${ }^{29}$ Vollandt, The Transmission of the Judaeo-Arabic Pentateuch, 27.

30 תורת היהודים ותורת השומרונים בהשוואה. The Torah: Jewish and Samaritan Versions Compared. A Side-by-Side Comparison of the Two Versions with Differences Highlighted. Arranged by Mark Shoulson, ([New Jersey]: M. Shoulson, 2006), 6.

${ }^{31}$ Gregor SCHWARB, «Vestiges of Qaraite Translations in the Arabic Translation(s) of the Samaritan Pentateuch», Intellectual History of the Islamicate World 1 (2013), 115156.

${ }^{32}$ Meira Polliack, The Karaite Tradition of Arabic Bible Translation. A Linguistic and Exegetical Study of Karaite Translations of the Pentateuch from the Tenth and Eleventh Centuries CE (Leiden - New York - Köln: Brill, 1997), 8-9. Cf. Schwarb, «Vestiges of Qaraite Translations», 118-119, n. 13. 
lectio שליחה documentada en otro manuscrito ${ }^{34}$, y en TS, tienen el mismo significado ('ofrenda'), pero con una interesante diferencia: mientras que שליחה tiene un significado neutro ${ }^{35}$, en cambio מנחה incluye un matiz agrario, pues significa concretamente 'ofrenda (de cereal)' ${ }^{36}$. Es interesante señalar que el término utilizado por $\mathrm{Sa}^{\prime}$ adyah es precisamente ב ב y y editadas por Shehadeh ${ }^{38}$. TN 4,4.5 lee en ambos casos קרבני ('ofrenda') ב ב bargo en Ge 4,3, al referirse a la ofrenda que presentó Caín, documenta un interesante préstamo que se corresponde semánticamente con el árabe $h a-$

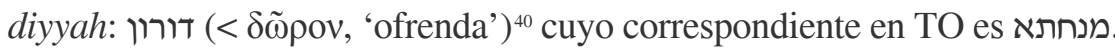

versos

5
$\operatorname{ArS}$

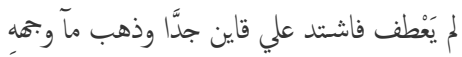

PS

לא שעה ויחר לקין מאד ויפלו פניו

Como en el caso anterior, la traducción árabe sigue literalmente el texto samaritano, aunque el sintagma פניו ('su rostro') ha dado lugar a una amplificatio en la versión árabe: $m \bar{a}$ ’ wağhihi ('la alegría de su rostro'),

${ }^{33}$ Gall (ed.), Der hebräische Pentateuch der Samaritaner, 5.

${ }^{34}$ M. Heidenheim (ed.), Die Samaritanische Pentateuch-Version. Die Genesis (Leipzig: Otto Schulze, 1884), 5.

${ }^{35}$ Cf. Abraham TAL, מילון הארמית של השומרונים/A Dictionary of Samaritan Aramaic (Leiden - Boston - Köln: Brill, 2000), II, 897b.

${ }^{36}$ Cf. TAL, מילון הארמית של השומרונים, 476b-477a.

${ }^{37}$ J. Derenbourg (ed.), Version arabe du Pentateuque de R. Saadia ben Iosef alFayyoûmî (Paris: Ernest Leroux, 1893), 9.

${ }^{38}$ Cf. SHEHAdeH, The Arabic Translation of the Samaritan Pentateuch, 16 (א), 17 (ב).

${ }^{39} \mathrm{La}$ misma lectura (incluso en 4,3) que recogen las dos versiones editadas por Lagarde, Materialien, I y II ad locum, así como IBN AL-ṬAYYIB, Commentaire sur la Genèse, I, 39, 40 (texto árabe).

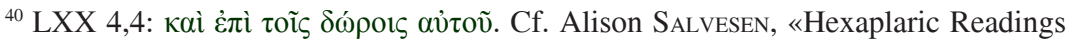
in Išo'dad of Merv's Commentary on Genesis», en The Book of Genesis in Jewish and Oriental Christian Interpretation. A Collection of Essays, eds. Judith Frishman y Lucas VAN RoMPay, TEG 5 (Louvain: Peeters, 1997), 241, n. 31. Acerca de este préstamo, véase Michael Sokoloff, A Dictionary of Jewish Palestinian Aramaic of the Byzantine Period (Ramat-Gan: Bar-Ilan University, 1992, 2ª reed.), 142a. 
זיווהון: וגהה :el esplendor de su rostro'), que coincide con la de Sa'adyah דאפוי (و.جمه هياء =) היאא (و) la de una de las dos versiones árabes cristianas editadas

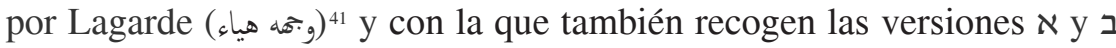
editadas por Shehadeh ${ }^{42}$

$\begin{array}{lll}\text { versos } & \text { ArS }\end{array}$

6

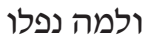

La versión árabe sigue, palabra a palabra, el texto samaritano y es exactamente la misma que presenta Sa'adyah (עאל וקל אללה לקין לם אשתד) וקל וקד

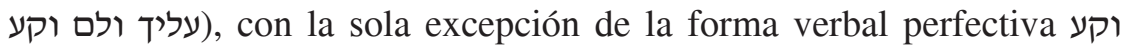

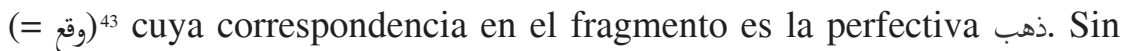
embargo, aunque no se corresponde con la versión editada por Shehadeh, sí que lo hace, y plenamente, con su versión $\beth^{44}$.

$\begin{array}{lll}\text { versos } & \text { ArS } & \\ & \text { PS }\end{array}$

פניך הלוא אם תטיב שאת ואם לא مآوبحك اليس ان يُشُ فرفعَُ وان لمُ

De nuevo, como en el v. 5, la estrategia utilizada para traducir פניך ('tu rostro') es el sintagma mā' wağhihi ('la alegría de tu rostro'), frente

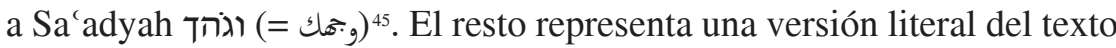
samaritano, que no se corresponde con la versión que ofrece $\mathrm{Sa}^{\prime}$ adyah ${ }^{46}$.

${ }^{41}$ LAGARDE, Materialien, II ad locum. Sobre esta versión (Pentateuco-catenae) realizada a partir de la Pešịttā, véase Georg GRAF, Geschichte der christlichen arabischen Literatur, «Studi e Testi» 118 (Città del Vaticano: Biblioteca Apostolica Vaticana, 1944), I, 106.

${ }^{42}$ Cf. Shehadeh, The Arabic Translation of the Samaritan Pentateuch, 16 (א), 17 (ב).

${ }^{43}$ La misma lectura en LAGARDE, Materialien, II ad locum.

${ }^{44}$ Cf. Shehadeh, The Arabic Translation of the Samaritan Pentateuch, 16 (א), 17 (ב).

${ }^{45}$ Idéntica lectura en LAGARDE, Materialien, I y II ad locum. Sobre la versión del vol. I, que corresponde a la tradición generada por la traducción de Sa'adyah, véase GRAF, Geschichte, I, 102.

${ }^{46}$ Cf. Derenbourg (ed.), Version arabe du Pentateuque de R. Saadia, 9. 
También aquí FAS presenta la misma estrategia que TN: זיוהן דאפיך (el esplendor de tu rostro'). En este caso, FAS exhibe una clara relación con las versiones $\mathrm{d}$ ב de Shehadeh, que presentan la misma lectura ${ }^{47}$.

$$
\begin{aligned}
& \begin{array}{lll}
\text { versos } & \text { ArS } & \text { PS }
\end{array} \\
& \text { תטיב לפתח חטאת רבץ ואליך תשוקתו يُشُن فباب الخطا أربص واليك مرجعه }
\end{aligned}
$$

El texto árabe sigue al samaritano palabra a palabra, recurriendo incluso a formas cognadas, como es el caso de أربص = רבץ y como en el caso anterior tampoco en éste se corresponde con la versión de $\mathrm{Sa}^{\text {'adyah }}{ }^{48}$. Una vez más, la correspondencia con las versiones de Shehadeh es patente, aunque en esta ocasión ב ב $\mathrm{y}$ presenten lecturas divergentes en el último término de la secuencia, que llevan a que FAS se encuentre más cerca de la tradición textual de $\mathrm{N}^{49}$.

$$
\text { versos ArS PS }
$$

ואתה תמשל בו ויאמר קין הבל אחיו وانت المستولي عليه فقال قاين لهابيل اخيه

Una vez más tenemos una traducción ad pedem litterae del texto samaritano y con diferencias notables con respecto a la versión de Sa'adyah. En este caso, en cambio, la relación con respecto a las versiones $\mathrm{x}$ y de Shehadeh se inclina a favor de $ב$, con la que FAS coincide plenamente ${ }^{50}$.

$$
\begin{array}{ccc}
\text { versos } & \text { ArS } & \text { PS } \\
8 & \text { נלכה השדה ויהי בהיותם בשדה }
\end{array}
$$

${ }^{47}$ Cf. Shehadeh, The Arabic Translation of the Samaritan Pentateuch, 16 (א), 17 (ב).

${ }^{48}$ Cf. Derenbourg (ed.), Version arabe du Pentateuque de R. Saadia, 9-10. Cf. asimismo Lagarde, Materialien, I y II ad locum e IBN AL-ṬAYYiB, Commentaire sur la Genèse, I, 40 (texto árabe).

${ }^{49}$ Cf. Shehadeh, The Arabic Translation of the Samaritan Pentateuch, 16 (א), 17 (ב)).

${ }^{50}$ Cf. SHeHADEH, The Arabic Translation of the Samaritan Pentateuch, 16 (א), 17 (ב)). 
Si bien el texto árabe es una traducción que sigue palabra a palabra el texto samaritano, sin embargo la lectio șahrā', que designa a un lugar yermo, a un páramo, es el equivalente de שדה, un término de significado desconocido ${ }^{51}$ que a partir del asirio šad $\hat{u}$ parece referir bien un lugar montañoso, a un campo abierto ${ }^{52}$, y del acadio $s \bar{a} d u$ a una tierra de pasto ${ }^{53}$. Frente a TN que lee אפי ברא" (campo (no cultivable); prado') ח חקלא ('campo') y TO que ofrece, la versión de Sa'adyah, distinta a la de nuestro fragmento, sin embargo también recurre a la misma lectio: צחר ('llano'), como resultado de una tradición judía adaptada por los traductores siriacos ${ }^{57}$, que mantienen algunas traducciones árabes cristianas (بقعة (ب) a (5) $^{58}$, aunque en otras hallamos posibilidades diversas como

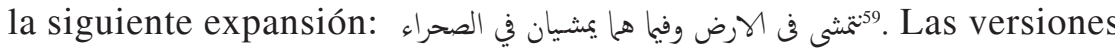
de Shehadeh en esta ocasión vuelven a diferir entre sí, siendo la versión la que coincide totalmente con FAS ${ }^{60}$. Interesante es la lectura que presenta (بريه), que parece depender de la forma cognada que exhibe TS: ברה, 'terreno (no cultivable)'

${ }^{51}$ Cf. F. Brown, S. R. Driver, Ch. A. Briggs, Hebrew and English Lexicon of the Old Testament (Boston - New York: Houghton Mifflin Company, 1906), 961a.

${ }^{52}$ The Assyrian Dictionary (Chicago, IL: The Oriental Institute, 1989), XVII/2, 49b, 59a.

${ }^{53}$ Wolfram von Soden, Akkadisches Handwörterbuch, 3 vols. (Wiesbaden: Harrassowitz, 1972, 1981, 1985), II, 1002a-b.

${ }^{54}$ Marcus JASTROW, A Dictionary of the Targumim, the Talmud Babli and Yerushalmi, and the Midrashic Literature (New York: Pardes House, 1959), I, 188b.

${ }^{55}$ Edward M. Cook, A Glossary of Targum Onkelos according to Alexander Sperber's Edition, SAIS 6 (Leiden - Boston: Brill, 2008), 98. Jubileos etiópico 4:3 lee 'campo' (wafr), véase The Book of Jubilees. Edited and translated by James C. Vanderkam, I, CSCO 510-511 (Louvain: Peeters, 1989), 22 (etiópico), II, 22 (inglés).

${ }^{56}$ Cf. Derenbourg (ed.), Version arabe du Pentateuque de R. Saadia, 10.

${ }^{57}$ Sebastian BRock, «Jewish traditions in Syriac Sources», Journal of Jewish Studies 30 (1979), 216-217.

${ }^{58}$ LAGARDE, Materialien, II ad locum.

${ }^{59}$ Lagarde, Materialien, I ad locum.

${ }^{60}$ Cf. Shenadeh, The Arabic Translation of the Samaritan Pentateuch, 16 (א), 17 (ב).

${ }^{61}$ BRÜLl (ed.), Das samaritanische Targum zum Pentateuch, 4. Cf. TAL, מילון הארמית של השומרונים, 112b. 
versos

8
$\operatorname{ArS}$

قام قاين الي هابيل اخيه فقتله
PS

ויקם קין אל הבל אחיו ויהרגהו

Traducción literal del texto samaritano, al que una vez más sigue la versión árabe palabra a palabra. En esta ocasión la versión del fragmento coincide totalmente con la que presenta Sa'adyah: קאם קין אלי הבל אכיה פקתלה TS, TO y TN también ofrecen la misma lectura, aunque en el tercer caso con amplificatio cuantitativa. Con respecto a las versiones ב ב ב ב de Shehadeh, la coincidencia plena vuelve a darse entre los textos de y FAS $^{63}$.

$$
\begin{aligned}
& \text { versos ArS PS }
\end{aligned}
$$

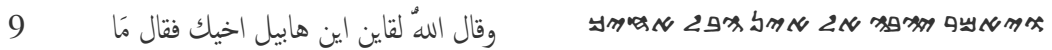

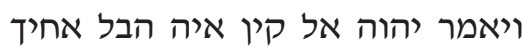

$$
\begin{aligned}
& \text { ויאמר לא }
\end{aligned}
$$

Como podemos apreciar, la versión árabe ofrece de nuevo una traducción del texto samaritano siguiendo la técnica del verbatim. TS presenta también una versión aramea paralela a PS. Hay que advertir que el copista al transcribir el texto en caracteres samaritanos no ha recogido el texto al completo, ya que ha omitido ויאמר לא ( en este caso la versión árabe del fragmento coincide de forma plena con las estrategias de traducción adoptadas por Sa'adyah. TO y TN siguen el THM. En cuanto a las versiones $x$ y de Shehadeh, aun no coincidiendo totalmente con ninguna de las dos ${ }^{64}$, es obvia la relación con 2 .

$$
\begin{aligned}
& \begin{array}{lll}
\text { versos } & \text { ArS } & \text { PS }
\end{array}
\end{aligned}
$$

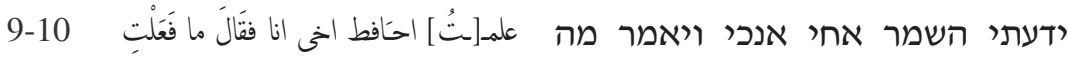

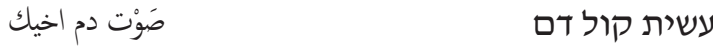

\footnotetext{
${ }^{62}$ Cf. Derenbourg (ed.), Version arabe du Pentateuque de R. Saadia, 10.

${ }^{63}$ Cf. Shehadeh, The Arabic Translation of the Samaritan Pentateuch, 16 (א), 17 (ב).

${ }^{64}$ Cf. SHEHAdeH, The Arabic Translation of the Samaritan Pentateuch, 16 (א), 17 (ב).
} 
Una vez más, la estrategia literalista del ad pedem litterae es evidente en la traducción árabe del fragmento, que si bien coincide en un segmento del v. 9 (احَافط اخى انا = אהפט אכי אנא), sin embargo exhibe diferencias en el resto del texto. También en esta ocasión el texto de FAS no concierta de forma total con las versiones ב ב y de Shehadeh, aunque el texto más cercano a FAS es de nuevo $\beth^{65}$.

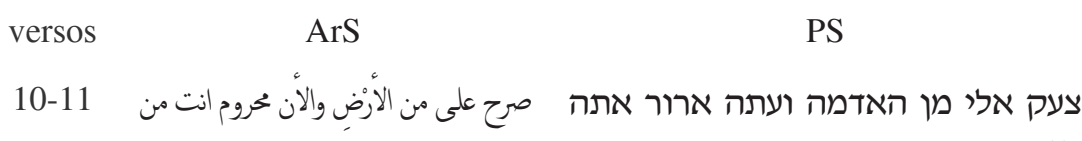

El texto árabe reproduce palabra a palabra al samaritano y nuevamente

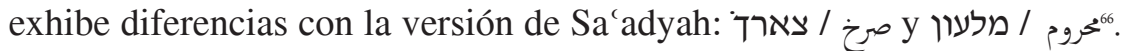
Tampoco se da una correspondencia plena entre FAS y las versiones $x$ y ב de Shehadeh ${ }^{67}$.
versos
$\operatorname{ArS}$
PS

11

الارض التى فتحت فاهَا لاخذ

האדמה אשר פצתה את פיה לקחת

Nuevamente tenemos una traducción literal del texto samaritano, que es semejante a la de Sa'adyah, si exceptuamos la última forma ver-

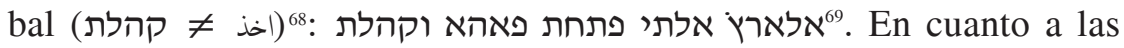
versiones $\mathrm{x}$ y de Shehadeh, la relación, esta vez de forma completa, se da con $ב^{70}$.

${ }^{65}$ Cf. Shehadeh, The Arabic Translation of the Samaritan Pentateuch, 16 (א), 17 (ב).

66 ملعون es también la lectura que ofrecen las dos versiones editadas en LAGARDE, Materialien, I y II ad locum.

${ }^{67}$ Cf. Shehadeh, The Arabic Translation of the Samaritan Pentateuch, 16 (א), 17 (ב).

${ }^{68}$ Cf. قبلت en la versión árabe de los LXX que recoge 'Alā' al-Dīn AL-BĀăīî, 'Alà alTawrāt, ed. Aḥmad Hiğāzī al-Saqqā (El Cairo: Dār al-Kutub, 1980 d.C./1400 H), 35.

${ }^{69} \mathrm{Cf}$. Derenbourg (ed.), Version arabe du Pentateuque de R. Saadia, 10.

${ }^{70}$ Cf. Shehadeh, The Arabic Translation of the Samaritan Pentateuch, 16 (א), 17 (ב). 
verso

$\operatorname{ArS}$

PS

$11-12$

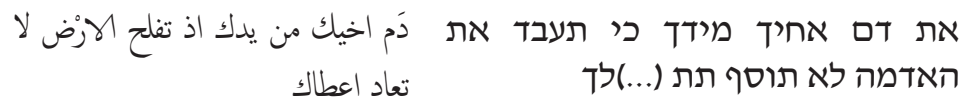

Como en todo el fragmento, traducción literal del texto samaritano, palabra a palabra, con una versión muy parecida a la de Sa'adyah: דם ביאכיך כל ידך האן תפלה אלארץ ולא תעוד אן תעטיך

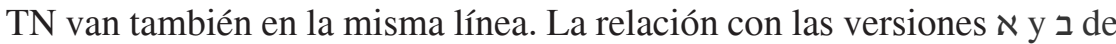
Shehadeh, vuelven a darse, pero en esta ocasión de modo casi completo, aunque no de forma total con $\mathbf{Z}^{72}$.

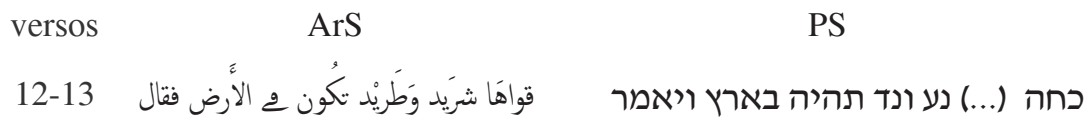

La traducción literal del texto samaritano, tampoco coincide con la versión de Sa'adyah: קוֹאהא נאיעא ונעידא תכון פי אלארץ . En cambio, FAS presenta en este segmento una correspondencia con las versiones de Shehadeh, lo que evidencia una vez más la relación textual con dichas versiones, aunque no se de en este caso una correspondencia plena como consecuencia de la ausencia en FAS del par preposición + afijo pronominal de 2. ${ }^{\mathrm{a}}$ p. m. sg. sك $\mathrm{J}^{74}$.

$\begin{array}{lll}\text { versos } & \text { ArS } & \text { PS }\end{array}$

קין אל יהוה גדול עוני מנשא הן قاين للهّ عَظْم ذنبي من ان تغتفر اذْطردتنى اليوم 14-13 גרשת אתי היום אלוח גור

La versión árabe, que concuerda con el texto samaritano, es muy seקין ללה דלנבי אעצם מן אן mejante a la de Sa'adyah salvo mínimos detalles קיגר פאן טרדתני אליום de tarada-yațrudu: (طردتنى טרדת יתי) טרד). De nuevo, aun cuando FAS

\footnotetext{
${ }^{71}$ Cf. Derenbourg (ed.), Version arabe du Pentateuque de R. Saadia, 10.

${ }^{72}$ Cf. Shehadeh, The Arabic Translation of the Samaritan Pentateuch, 16 (א), 17 (ב).

${ }^{73}$ Cf. Derenbourg (ed.), Version arabe du Pentateuque de R. Saadia, 10.

${ }^{74}$ Cf. Shenadeh, The Arabic Translation of the Samaritan Pentateuch, 16 (א), 17 (ב).

${ }^{75}$ Cf. Derenbourg (ed.), Version arabe du Pentateuque de R. Saadia, 10.
} 
exhibe una clara relación con las versiones $\mathrm{x}$ y editadas por Shehadeh, sin embargo la correspondencia del texto no es completa con estas dos versiones ${ }^{76}$.

$$
\begin{aligned}
& \begin{array}{lll}
\text { versos } & \text { ArS } & \text { PS }
\end{array} \\
& \text { מעל פני האדמה ומפניך אסתר م علي وجِ الارضِ و م حصرتك احتجب } 14
\end{aligned}
$$

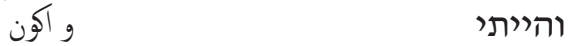

Sigue literalmente el texto samaritano y no coincide con la versión de Sa'adyah: יאן וגה אלארץ הל מן בין ידיך אנסתר ואן כנת . Para este segmento la correspondencia con las versiones $\mathrm{x}$ e editadas por Shehadeh es total ${ }^{78}$.

$$
\begin{aligned}
& \begin{array}{lll}
\text { versos } & \text { ArS } & \text { PS }
\end{array}
\end{aligned}
$$

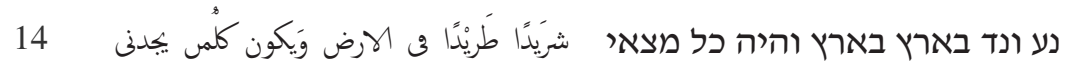

$$
\begin{aligned}
& \text { יהרגני }
\end{aligned}
$$

Correspondencia plena con el texto samaritano, muy parecida a la versión de Sa'adyah: נאיעא ונעידא פי אלארץ כאן כל מן וגדני יקתלני הaste. En este

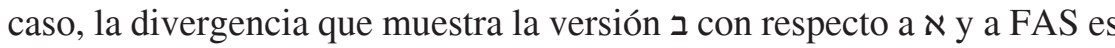
evidente, siendo estas dos últimas la misma, si advertimos que la lectio ב ב en presenta un error de la transmisión manuscrita (paleográficamente comprensible) por la correcta lectura طريدًا

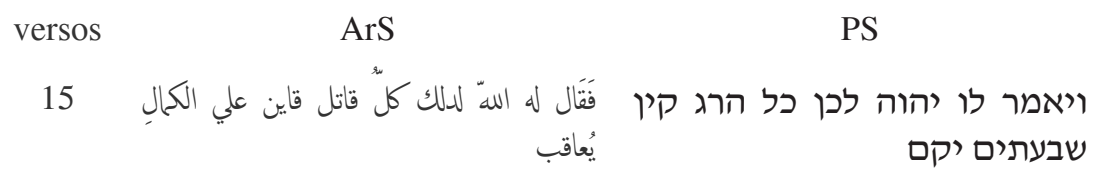

La literalidad con respecto al texto samaritano vuelve a ser evidente, si bien שك الكال no es la equivalencia del teologismo שבתים , sino un susti-

${ }^{76}$ Cf. Shehadeh, The Arabic Translation of the Samaritan Pentateuch, 16 (א), 17 (ב).

${ }^{77}$ Cf. Derenbourg (ed.), Version arabe du Pentateuque de R. Saadia, 10.

${ }^{78}$ Cf. SHEHAdeH, The Arabic Translation of the Samaritan Pentateuch, 16 (א), 17 (ב).

${ }^{79}$ Cf. Derenbourg (ed.), Version arabe du Pentateuque de R. Saadia, 10.

${ }^{80}$ Cf. Shehadeh, The Arabic Translation of the Samaritan Pentateuch, 16 (א), 17 (ב).

${ }^{81}$ Las dos versiones editadas en Lagarde, Materialien, II ad locum, recogen سبعة دفعات (I ad locum) y كثيرا (II ad locum). 
tuto para indicar una suerte de pena capital ${ }^{82}$. Una vez más, la traducción árabe de nuestro fragmento parece una reelaboración de la versión de Sa'adyah: קאל אללה לדלך כל מן קתל קין יקאד בה כתירה , probablemente corregida con textos diversos. Un ejemplo de ello es la construcción kull qātil, que no representa la traducción de Sa'adyah: כל מן קתל (cf.

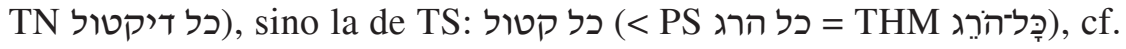

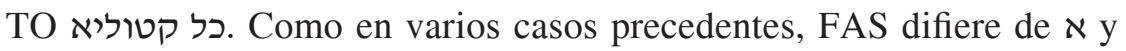
se corresponde plenamente con la versión ב de los textos editados por Shehadeh.

\section{CONCLUSIÓN}

El fragmento del texto árabe samaritano T-S Ar.1a.136 es una muestra más de la cadena de especímenes manuscritos derivados de la versión que realizará $\mathrm{Sa}$ 'adyah ha-Ga'ôn. Sabemos que el textus receptus de la traducción árabe elaborada por $\mathrm{Sa}^{\prime}$ adyah $^{84}$ difiere sustancialmente de las versiones que corrieron de Sa'adyah y que fueron utilizadas por otros autores judíos como Dunāš b. Labrāṭ o Yěhudah b. Bal'am entre otros. ${ }^{85}$

La traducción del fayyūmí fue paulatinamente alterada por medio de las readaptaciones que, entre otros ${ }^{86}$, elaboraron los autores samaritanos hasta llegar a alcanzar la forma que presenta el llamado textus receptus de $\mathrm{Abū} \mathrm{Sa}{ }^{\top} \overline{1} \mathrm{~d}$, versión que difiere considerablemente de la que llevara a cabo Sa'adyah. El proceso, continuado en el tiempo en el seno de la comunidad samaritana, es además complejo por la diversidad de versiones existentes dentro de la misma tradición textual.

Éste es precisamente el caso del fragmento incluido en T-S Ar.1a.136. Este fragmento, que forma parte de la misma tradición que las versiones א y editadas por Shehadeh como testigos resultantes de la revisión que realizara $\mathrm{Abū} \mathrm{Sa}{ }^{\prime} \overline{1} d$ en el en el siglo XIII, aporta, sin embargo, una serie

${ }^{82}$ Cf. Su-Min Ri, Commentaire de la Caverne des Trésors, 189.

${ }^{83}$ Cf. Derenbourg (ed.), Version arabe du Pentateuque de R. Saadia, 10.

${ }^{84}$ Cf. Derenbourg (ed.), Version arabe du Pentateuque de R. Saadia.

${ }^{85}$ SAmIR, «Édition de l'«Untersuchungen», págs. 32-70, passim.

${ }^{86}$ Joseph F. RHode, The Arabic versions of the Pentateuch in the Church of Egypt (Washington: The Catholic University of America, 1921), 36, 45-46, n. 1, 117. 
de lecturas que marcan diferencias con respecto al texto $\mathrm{N}$ y su texto se adecúa a $ב$.

Pese a que el fragmento incluido en T-S Ar.1a.136 presenta una versión muy cercana $\mathrm{a}$, sin embargo las variantes de lectura que exhibe ב nos permiten constatar que el fragmento de T-S Ar.1a.136 representa en realidad un eslabón más en el largo y variado proceso de revisióntransmisión textual experimentado por esta versión, que exhibe una lectura independiente ${ }^{87}$.

Ofrecemos a continuación una tabla sinóptica con las tres versiones, las dos editadas por Shehadeh y T-S Ar.1a.136 separando a aquellas dos con el fin de que puedan apreciarse las divergencias de lectura que presentan entre ellas y sobre todo con respecto a T-S Ar.1a.136. Estas lecturas divergentes, como se verá, prueban que nuestro texto representa una variante más en el proceso de revisión realizado por $\mathrm{Abū} \mathrm{Sa}$ ‘ $\overline{1} \mathrm{~d}$.

${ }^{87}$ NIESSEN, en http://www.lib.cam.ac.uk/Taylor-Schechter/fotm/november-2007/ 
الله الى هابيل واللى هديته والى قايني والمي هديته لم يعطف فاشتيّ

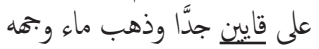
وقال الله لقايبن لمج اشتّد عليك فيك

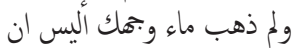

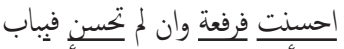

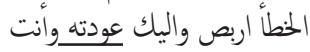
المستولي عليه فقال قايين لهابيل اخيه نمضي المى الصحراء وكان عند كونها في الصحراء قام قايين الى الى هابيل اخيه فقتله وقال الله لقايبن

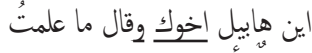
احافظ أخي انا فقال ما صنعت اخت مات عان

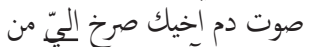

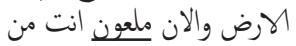
الارض التي فتحت فاها لاخذ دم الحرض

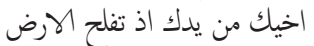
لا تعاود اعطاء قواها لك شئ شريدًا

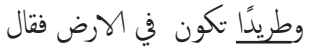
قايني لله عظم ذنبي من ان يُغفّر ان طردتي اليوم مى على وجه

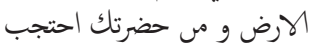
و اكون شريدًا طريدًا في الهرض احضي ويكون كل مس وجدني يقتلني فقال

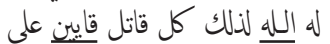
الكال يعاقب اله
الهُ علي هابيل وعلي هديته وعلي

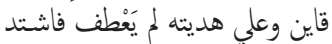
علي قاين جدَّا وذهب مآ وبحهن فقال

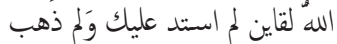
مآ وبحك اليس ان يحُسُ فرفقَهُ

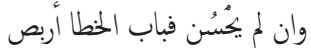
واليك مرجعه وانت المستولي

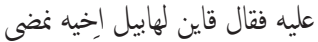

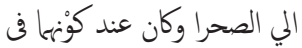
الصحرآَ قام قاين الي هابيل اخيه

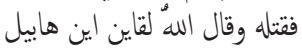

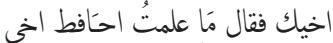

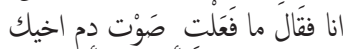

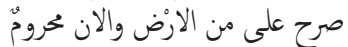
انت من الارض التى فتحت فرّن فاهًا

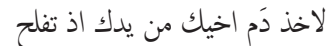

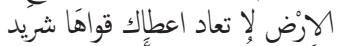

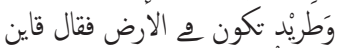

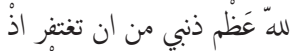

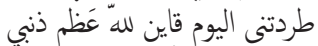
من ان تغتفر اذ طردتنى اليوم مى لئ علي وجه الارض و من حصرتك لفنك

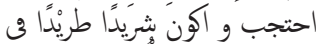
1ارض وَيكون كلمي، يجدنى يقتلنغ

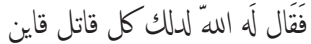
علي الكال يُعاقب
الله المي هابيل والي هديته والمي

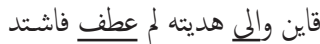
علي ايين جدًا وذهب ماءِ وبتهه وقال الله المي قايني لماذا صعب وديب

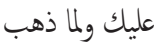
ما وبحك اليس ان احسنت فرفعة وان لم تحسن في باب الخنطا اربص

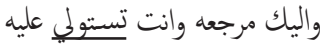
فقال قايبن الي هابيل اخيه نمضي وني للمييه وكان عند كونها في التريه قام قايين الى هابيل اخيه وقتله وقال الله الي قايني اين هابيل اخليك

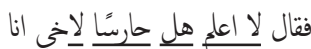

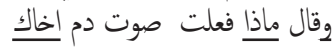

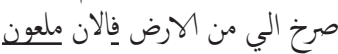

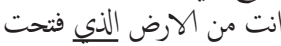

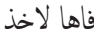

دم اخاكِ من يدك اذ تفلح الها رض لا عادت تعطي_قواها لك شريد وطريد تكون في الهرض فقال قايبن لله عظم ذنبي من ان يغتف ان طردتني اليوم مى على وجه

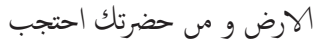

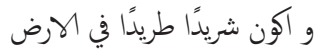
ويصير كل مس وجدني يقتلني فقال له الله بهلسب كل مل قاتل قائين على الكهال يعاقب له لـ

Recibido: $23 / 02 / 2013$

Aceptado: 10/11/2013 